\title{
Comparison of Estimated Protein Output and Urine Protein:Creatinine Ratio in First and Second Voids with 24-Hour Urine Protein
}

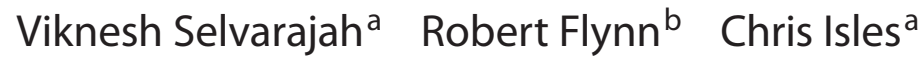

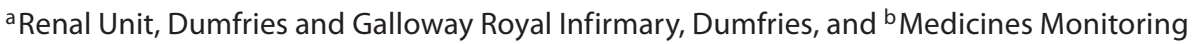 \\ Unit, University of Dundee, Ninewells Hospital \& Medical School, Dundee, UK
}

\section{Key Words}

Albumin:creatinine ratio - Albuminuria $\cdot$ Estimated protein output $\cdot$ Kidney disease $\cdot$

Protein:creatinine ratio $\cdot$ Proteinuria

\begin{abstract}
Background: Current UK guidelines for the identification, management and referral of chronic kidney disease advise an early-morning urine sample for the albumin:creatinine ratio or the protein:creatinine ratio $(P C R)$ in order to quantify proteinuria. Estimated protein output (EPO) is an alternative and possibly better method of quantifying proteinuria which takes lean weight into consideration. Methods: We carried out a single-centre study of 36 adult patients with proteinuric nephropathy over a period of 18 months. Urinary PCR and EPO estimates of 24-hour urine protein were compared with 24-hour urine collections by Bland-Altman analysis. Results: Average 24-hour urine protein was $1.6 \mathrm{~g}$ (range $0.2-5.1 \mathrm{~g}$ ). Best agreement with 24-hour protein was for first-void EPO (limits of agreement $0.33-1.59)$ followed by a second-void EPO (0.40-1.76), then second-void PCR (0.40-2.08) and lastly first-void PCR (0.28-2.03). None of the differences between estimates of urine protein excretion and 24-hour urine protein were statistically significant. All estimates of protein output had wide confidence intervals confirming that spot urine samples, while simple and convenient to do, are imprecise measures of 24-hour urine protein excretion. Conclusion: When estimating 24-hour urine protein from a spot urine sample, EPO may be marginally more accurate than PCR, and first-void urine samples slightly better than second-void urine samples, but a first- or second-void PCR will suffice in most instances.
\end{abstract}




\section{Introduction}

Measurement of urine protein plays a vital part in the assessment of patients with renal disease and also predicts those who will develop progressive renal failure [1,2]. The 24-hour urine collection was for a long time the method of choice for quantifying proteinuria but is no longer recommended on the grounds of inconvenience and imprecision due to human error in collection. In its place, UK and American guidelines advise an early-morning urine sample to assess the albumin:creatinine ratio (ACR) or the protein:creatinine ratio (PCR) [3-6]. Estimated protein output (EPO) may be an even better method of quantifying proteinuria as it takes lean body weight into consideration [7]. Against this background, we carried out a study to determine which measure gives the best estimate of 24-hour urine protein: first or second void of the day? EPO or PCR?

\section{Materials and Methods}

\section{Study Design}

This was a prospective single-centre study of patients with proteinuric nephropathies attending our nephrology clinic over an 18-month period.

\section{Patients}

We recruited 41 patients for the study according to the following criteria: not on dialysis, age $>18$ years, absence of pregnancy and 24 -hour urine protein $<6 \mathrm{~g} /$ day. Previous studies have shown a poor correlation between PCR and 24-hour protein excretion at higher levels of proteinuria [8-10]. Completeness of each 24-hour urine collection was judged by ratio of measured:expected $\mathrm{Cr}$, a method previously described in the literature $[11,12]$. We excluded patients whose measured:expected Cr ratio lay outwith the range 0.5-2.0.

\section{Methods}

Patients provided a 24-hour urine collection in 3 containers: container A for the first void, container $\mathrm{B}$ for the next void and container $\mathrm{C}$ for all urine passed thereafter up to and including the first void the following morning. We combined the urine in containers $\mathrm{B}$ and $\mathrm{C}$ to give a 24-hour urine collection and used this as the gold standard in our study. We gave each patient verbal and written instructions to assist with their collections. Lean weight and EPO were calculated using standard formulae (box 1). Serum and urinary Cr concentrations were determined by the kinetic Jaffé method using the same Roche modular analyser. Urine protein concentrations were determined with the turbidimetric method using benzethonium chloride.

\section{Statistical Analysis}

EPO and PCR for containers A and B were compared with B + C (24-hour urinary protein) by Bland-Altman plot. Bland-Altman analysis is a way of measuring the degree of agreement when linear correlation is inappropriate due to measurements being inherently related $[13,14]$. To do this, we plotted the difference between estimated and actual measurements of proteinuria (e.g. first-void EPO minus 24-hour urine protein) against the average of the measurements (e.g. first-void EPO plus 24-hour urine protein divided by 2). Because the data were positively skewed, we used log-transformed data to calculate the limits of agreement and $95 \%$ confidence intervals, using the approach of Bland and Altman $[15,16]$. The plots used the transformed data and the limits of agreement were back transformed to allow interpretation. The data were plotted using SPSS version 15.0 and the confidence intervals calculated using Microsoft Excel. 
Fig. 1. Relation between firstvoid (A) EPO and 24-hour urine protein (conventional plot).

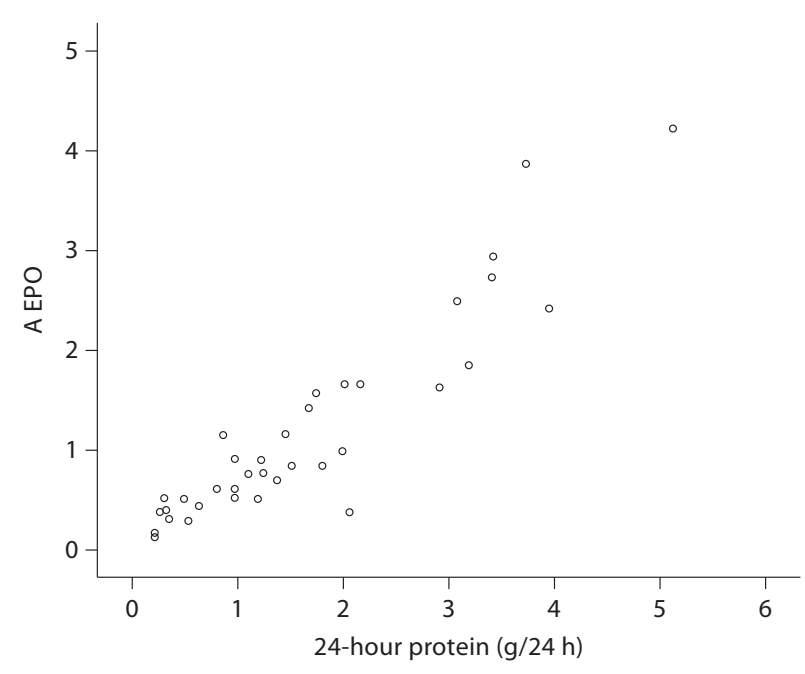

Box 1. Formulae for EPO and lean weight

$\mathrm{EPO}=\mathrm{PCR} \times \mathrm{ECE}$

$\mathrm{ECE}=(140-$ age $) \times$ lean weight $(\mathrm{kg}) \times 0.2(\times 0.85$ if female $)$

Lean weight $=22.5 \times$ height $\left(\mathrm{m}^{2}\right)$

\section{Ethics}

All patients were informed about the purposes of the study and gave written consent. The study was approved by the Office for Research Ethics Committees of Northern Ireland (reference No. 05/NIRO5/40).

\section{Results}

Forty-one patients were recruited. We excluded 3 patients with very high protein output ( $>6 \mathrm{~g} / 24 \mathrm{~h}$ ) and 2 with incomplete collections. Twenty-five of the remaining 36 patients were male and 11 were female. Their average age was 63 (range 35-86) years. Average 24-hour urine protein was $1.6 \mathrm{~g}$ (range $0.2-5.1 \mathrm{~g}$ ). Five (14\%) patients had nephrotic-range proteinuria (>3 g/24 h). Mean estimated glomerular filtration rate was 34 (range 11-107) $\mathrm{ml} / \mathrm{min} /$ $1.73 \mathrm{~m}^{2}$. The most common cause of underlying kidney disease was diabetic nephropathy $(10,28 \%)$ followed by hypertensive nephrosclerosis $(5,14 \%)$, idiopathic membranous nephropathy $(5,14 \%)$ and IgA nephropathy $(3,8 \%)$.

The relation between first-void EPO and 24-hour urine protein is shown in figure 1 (conventional plot) and figure 2 (Bland-Altman plot). The horizontal lines in figure 2 show the limits of agreement of the differences between first-void EPO and 24-hour urine protein. The limits of agreement for each of the 4 comparisons with 24-hour urine are shown in table 1. The closer these are the better the agreement. Best agreement with 24-hour urine protein was for first-void EPO with limits of agreement of 0.33-1.59. This means that the actual protein output is likely to lie between 33 and $159 \%$ of the estimated value. This was followed by sec- 
Fig. 2. Relation between firstvoid (A) EPO and 24-hour urine protein (Bland-Altman plot). The horizontal lines show the limits of agreement of the differences between first-void EPO and 24-hour urine protein.

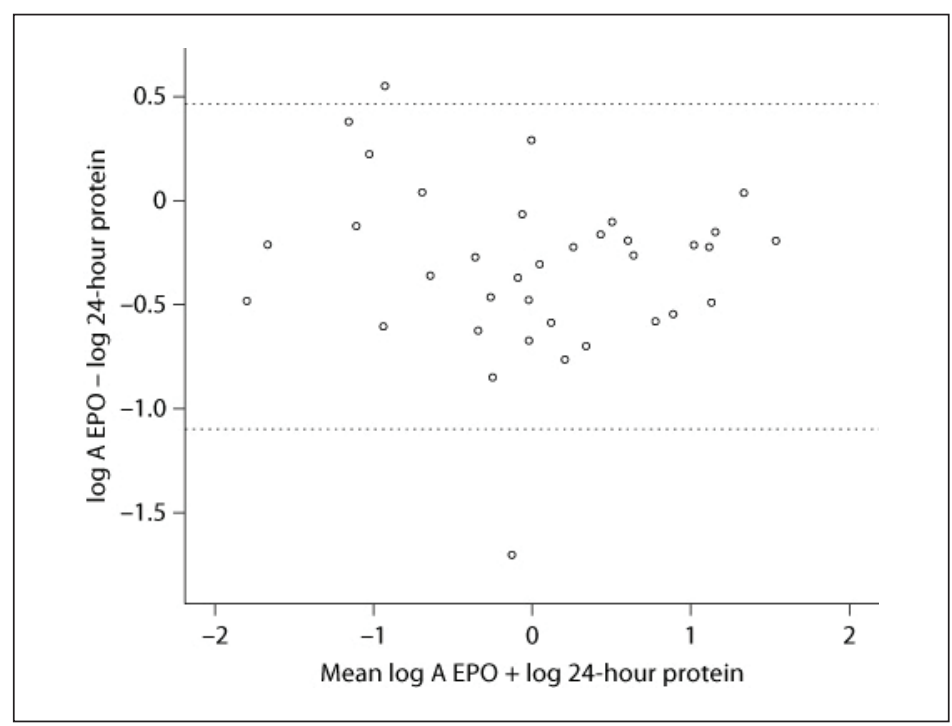

Table 1. Limits of agreement using Bland-Altman analysis

\begin{tabular}{|c|c|c|}
\hline & $\begin{array}{l}\text { Lower limit of } \\
\text { agreement }(95 \% \mathrm{CI})\end{array}$ & $\begin{array}{l}\text { Upper limit of } \\
\text { agreement }(95 \% \mathrm{CI})\end{array}$ \\
\hline \multicolumn{3}{|l|}{ EPO } \\
\hline First void & $0.33(0.26-0.42)$ & $1.59(1.26-2.01)$ \\
\hline Second void & $0.44(0.36-0.55)$ & $1.76(1.44-2.16)$ \\
\hline \multicolumn{3}{|l|}{ PCR } \\
\hline First void & $0.28(0.21-0.38)$ & $2.03(1.51-2.72)$ \\
\hline Second void & $0.40(0.32-0.52)$ & $2.08(1.63-2.65)$ \\
\hline
\end{tabular}

ond-void EPO (0.40-1.76), then second-void PCR (0.40-2.08) and finally first-void PCR $(0.28-2.03)$. None of the differences between the estimates of urine protein excretion and 24hour urine protein were statistically significant. A sensitivity analysis showed our findings were not significantly influenced by extremes of age ( $<40$ and $\geq 75$ years) or body mass index $\left(<18.5\right.$ and $\left.\geq 35 \mathrm{~kg} / \mathrm{m}^{2}\right)$ though the results of this are difficult to interpret because 30 of 36 patients lay within the limits for age and 32 patients lay within the limits for body mass index.

\section{Discussion}

Proteinuria is an important risk factor not only for progression of renal failure but also for the development of cardiovascular disease in patients with chronic kidney disease (CKD) [17]. It can be monitored at intervals to assess disease progression and response to antiproteinuric therapy. Both SIGN and NICE have concluded that dipstick testing should no longer be used to confirm the presence or absence of proteinuria at low levels of protein excretion, and that some form of quantitative test should be used instead $[5,6]$. No one will regret the passing of the 24-hour urine collection which is now recognised to be too cumbersome, time consuming and imprecise for everyday clinical use. In its place, both UK and US guidelines recommend either the ACR or the PCR [3-6]. ACR has greater sensitivity than PCR for detection of low levels of proteinuria and is the recommended method for people with diabetes $[5,6]$. In pa- 
tients with established CKD and those without diabetes, measurement of PCR is an acceptable alternative $[5,6]$. Both ACR and PCR predict subsequent progression of renal disease $[5,6,18]$. PCR may also be more sensitive than ACR at detecting clinically significant proteinuria [19]. Partly because we were dealing with patients with established proteinuria and partly because of the lower cost of the assay, we chose to use the PCR rather than ACR in this study.

Our main finding is that first-void EPO is slightly more accurate than estimates of proteinuria based on second void or PCR. The differences were marginal and statistically insignificant, implying that a first- or second-void PCR will suffice in most instances when quantifying proteinuria. A strength of our study is that we ascertained the completeness of our gold standard 24-hour urine collections by excluding those with measured/estimated $\mathrm{Cr}$ ratios that lay outwith the range $0.5-2.0$. The main limitation was that all four estimates of protein output had wide confidence intervals, as in 3 previous studies evaluating the accuracy of PCR [20-22]. This issue has also been highlighted in a study showing that the use of PCR to estimate 24-hour protein excretion leads to significant numbers of false-positive and false-negative diagnoses of glomerulonephritis flares in patients with systemic lupus erythematosus [12]. The convenience of estimating protein output from a single specimen of urine is attractive but does not and cannot take into account diurnal fluctuations of protein and Cr excretion [20, 23, 24].

The jury on the timing of a spot urine sample is still out [7,25-29]. The NICE Guideline Development Group states that proteinuria is more likely to be detected in an early-morning sample because early-morning urine is more concentrated, while recognising that advice to test only early-morning urine would cause practical difficulties for service organisation and might inhibit opportunistic testing [6]. Neither NICE nor SIGN make recommendations on the timing of the urine sample for PCR (or ACR) [5, 6]. The KDOQI guideline recommends an early-morning sample but uses as its evidence base 7 studies, only one of which declared in favour of a first void [4]. It has been proposed that first-void samples are preferable because they show best correlation with 24-hour protein excretion and reduce inaccuracy due to orthostatic proteinuria [4]. Ruggenenti et al. [21] found that random urine samples were as good as early-morning urine samples at predicting the rate of loss of kidney function in nondiabetic CKD. Guy et al. [29] found that early-morning urine, second or third voids would be equally effective at predicting 24 -hour urine protein loss.

Is EPO a better estimate of 24-hour urine protein than PCR? EPO is given by the formula $\mathrm{EPO}=\mathrm{PCR} \times$ estimated $\mathrm{Cr}$ excretion $(\mathrm{ECE})$, where $\mathrm{ECE}=140-$ age $\times$ lean weight $(\mathrm{kg}) \times$ 0.2 ( $\times 0.85$ if female). This is a modification of the Cockcroft-Gault equation that has been previously validated [30]. PCR can be used to approximate 24 -hour urine protein if one assumes an individual's ECE is $10 \mathrm{mmol} / \mathrm{day}$, as suggested by UK guidelines [3]. This is a reasonable assumption for a middle-aged adult weighing around $70 \mathrm{~kg}$, in whom a PCR of $100 \mathrm{mg} /$ mmol will approximate to a 24-hour urine protein of $1 \mathrm{~g}$, but is less likely to hold at extremes of age or body weight. Ginsberg et al. [7] have shown that EPO correlated closely $(r=0.93)$ with 24-hour urine protein, although no attempt was made to compare the results of PCR with EPO in that analysis. Our study shows that first-void EPO is slightly more accurate than estimates of proteinuria based on second void or PCR, but that the differences are small and statistically insignificant. The attraction of PCR is its simplicity and the fact that it does not require age and gender to be entered into an equation or lean body weight to be calculated.

The aims of our study were to determine the relative benefits of four different estimates of urine protein excretion. In the event we showed that the limits of agreement for each of the four spot tests and 24-hour urine protein were considerably greater than the differences between the four tests themselves. The main drawback of spot urine tests therefore is that none predicts 24 -hour urine protein as accurately as it was hoped they would do. This caveat notwithstanding, the knowledge that spot urine samples with all their imperfections still predict subsequent progression of renal disease allows us to conclude that the conve- 
nience of a first- or second-void PCR is likely to outweigh its limitations except possibly in very young or very old subjects and at extremes of body weight. Further larger studies are required to determine the best timing for spot urine samples and whether EPO is a better estimate of 24-hour urine protein than PCR.

\section{Disclosure Statement}

The authors of this paper declare no conflicts of interest.

\section{References}

1 Lea J, Greene T, Herbert L, et al: The relationship between magnitude of proteinuria reduction and risk of end-stage renal disease. Results of the African American Study of Kidney Disease and Hypertension. Arch Intern Med 2005;165:247-253.

2 Peterson JC, Adler S, Burkart JM, et al: Blood pressure control, proteinuria and progression of renal disease: the Modification of Diet in Renal Disease Study. Ann Intern Med 1995;123:754-762.

3 Joint Specialty Committee for Renal Disease, Royal College of Physicians of London and the Renal Association: Chronic Kidney Disease in Adults: UK Guidelines for Identification, Management and Referral. London, Royal College of Physicians, 2005 (http://www.rcplondon.ac.uk/pubs/books/ kidney/ckd_clinical_guide.pdf).

4 National Kidney Foundation/Kidney Disease Outcomes Quality Initiative: NKF K/DOQI Clinical Practice Guidelines for Chronic Kidney Disease. Guideline 5: assessment of proteinuria: Am J Kidney Dis 2002;39:S93-S201.

5 Scottish Intercollegiate Guidelines Network: Diagnosis and management of chronic kidney disease. Edinburgh, SIGN, 2008 (http://www.sign.ac.uk/pdf/sign103.pdf).

6 National Collaborating Centre for Chronic Conditions. Chronic Kidney Disease: National Clinical Guideline for Early Identification and Management in Adults in Primary and Secondary Care. London, Royal College of Physicians, 2008 (http://www.nice.org.uk/nicemedia/pdf/CG073FullGuideline. pdf).

7 Ginsberg JM, Chang BS, Matarese RA, Garella S: Use of single voided urine samples to estimate quantitative proteinuria. N Engl J Med 1983;309:1543-1546.

8 Lane C, Brown M, Dunsmuir W, Kelly J, Mangos G: Can spot urine protein/creatinine ratio replace $24 \mathrm{~h}$ urine protein in usual clinical nephrology? Nephrology 2006;11:245-249.

9 Antunes VVH, Veronese FJV, Morales JV: Diagnostic accuracy of the protein/creatinine ratio in urine samples to estimate 24 -h proteinuria in patients with primary glomerulopathies: a longitudinal study. Nephrol Dial Transplant 2008;23:2242-2246.

10 Lee HA, Birmingham DJ, Shidham G, Rovin B, Nagaraja HN, Yu CY: Random spot urine protein/ creatinine ratio is unreliable for estimating 24 -hour proteinuria in individual systemic lupus erythematosus nephritis patients. Nephron Clin Pract 2009;113:c177-c182.

11 Wilmer WA, Rovin BH, Herbert CJ, Rao SV, Herbert LA: Management of glomerular proteinuria: a commentary. J Am Soc Nephrol 2003;14:3217-3232.

12 Birmingham DJ, Rovin BH, Sindham G, Nagaraja HN, Zhou X, Bissel M, Yu C-Y, Herbert LA: Spot urine protein/creatinine ratios are unreliable estimates of $24 \mathrm{~h}$ proteinuria in most systemic lupus erythematosus nephritis flares. Kidney Int 2007;72:865-870.

13 Bland JM, Altman DG: Statistical methods for assessing agreement between two methods of clinical measurement. Lancet 1986;1:307-310.

14 Bland JM, Altman DG: Comparing methods of measurement: why plotting differences against standard methods is misleading. Lancet 1995;346:1085-1087.

15 Bland JM, Altman DG: Measuring agreement in method comparison studies. Stat Methods Med Res 1999;8:135-160. 
16 Hamilton C, Stamey J: Using Bland-Altman to assess agreement between two medical devices - don't forget the confidence intervals! J Clin Monit Comput 2007;21:331-333.

17 Perkovic V, Verdon C, Niromiya T, Barzi F, Cassa A, et al: The relationship between proteinuria and coronary risk: a systematic review and meta-analysis. PLoS Med 2008;5:e207.

18 Methven S, MacGregor MS, Traynor JP, Hair M, O’Reilly DSJ, Deighan CJ: Comparison of urinary albumin and urinary total protein as predictors of patient outcomes in CKD. Am J Kidney Dis 2011; 57:21-28.

19 Methven S, MacGregor MS, Traynor JP, O'Reilly DSJ, Deighan CJ: Assessing proteinuria in chronic kidney disease: protein-creatinine ratio versus albumin-creatinine ratio. Nephrol Dial Transplant 2010;25:2991-2996.

20 Koopman MG, Krediet RT, Zuyderhoudt FJ, De Moor EA, Arisz L: A circadian rhythm of proteinuria in patients with a nephrotic syndrome. Clin Sci (Lond) 1985;69:395-401.

21 Ruggenenti P, Gaspari F, Perna A, Remuzzi G: Cross sectional longitudinal study of spot morning urine protein:creatinine ratio, 24 hour urine protein excretion rate, glomerular filtration rate and end stage renal failure in chronic renal disease in patients without diabetes. BMJ 1998;316:504-509.

22 Mitchell SCM, Shedon TA, Shaw AB: Quantification of proteinuria: a re-evaluation of the protein/ creatinine ratio for elderly subjects. Age Ageing 1993;22:443-447.

23 Sadjadi SA, Jaipaul N: Correlation of random urine protein creatinine $(\mathrm{P}-\mathrm{C})$ ratio with 24-hour urine protein and P-C ratio, based on physical activity: a pilot study. Ther Clin Risk Manag 2010;6:351-357.

24 Shidham G, Herbert LA: Controversies in nephrology: timed urine collections are not needed to measure urine protein excretion in clinical practice. Am J Kidney Dis 2006;47:8-14.

25 Chu NF, Ferng SH, Shieh SD, Shyh TP, Chu PL: Assessment of proteinuria by using the protein/creatinine ratio of single-voided urine. J Formos Med Assoc 1990;89:657-660.

26 Wilson DM, Anderson RL: Protein-osmolality ratio for the quantitative assessment of proteinuria from a random urinalysis sample. Am J Clin Pathol 1993;100:419-424.

27 Steinhasulin F, Wauters J: Quantification of proteinuria in kidney transplant patients: accuracy of protein/creatinine ratio. Clin Nephrol 1995;43:110-115.

28 Yoshimoto M, Tsukahara H, Saito M, et al: Evaluation of variability of proteinuria indices. Pediatr Nephrol 1990;4:136-139.

29 Guy M, Borzomato JK, Newall RG, Karla PA, Price CP: Protein and albumin-to-creatinine ratios in random urines accurately predict $24 \mathrm{~h}$ protein and albumin loss in patients with kidney disease. Ann Clin Biochem 2009;46:468-476.

30 Lim WH, Lim EM, McDonald S: Lean body mass-adjusted Cockcroft and Gault formula improves the estimation of glomerular filtration rate in subjects with normal-range serum creatinine. $\mathrm{Ne}$ phrology 2006;11:250-256. 